\title{
Article \\ Actionable Genomics in Clinical Practice: Paradigmatic Case Reports of Clinical and Therapeutic Strategies Based upon Genetic Testing
}

\author{
Merlin G. Butler ${ }^{1}\left(\mathbb{D}\right.$, Daniel Moreno-De-Luca ${ }^{2,3}$ (D) and Antonio M. Persico $4,5, *$ (D) \\ 1 Departments of Psychiatry \& Behavioral Sciences and Pediatrics, University of Kansas Medical Center, \\ Kansas City, KS 66160, USA; mbutler4@kumc.edu \\ 2 Genomic Psychiatry Consultation Service, Verrecchia Clinic for Children with Autism and Developmental \\ Disabilities, Bradley Hospital, East Providence, RI 02915, USA; daniel_moreno_de_luca@brown.edu \\ 3 Division of Child and Adolescent Psychiatry, Department of Psychiatry and Human Behavior, \\ Warren Alpert Medical School of Brown University, Providence, RI 02903, USA \\ 4 Department of Biomedical, Metabolic and Neural Sciences, University of Modena and Reggio Emilia, \\ I-41125 Modena, Italy \\ 5 Child and Adolescent Neuropsychiatry Program, Modena University Hospital, I-41125 Modena, Italy \\ * Correspondence: antonio.persico@unimore.it
}

Citation: Butler, M.G.;

Moreno-De-Luca, D.; Persico, A.M. Actionable Genomics in Clinical Practice: Paradigmatic Case Reports of Clinical and Therapeutic Strategies Based upon Genetic Testing. Genes 2022, 13, 323. https://doi.org/ 10.3390 /genes 13020323

Academic Editor: Donato Gemmati

Received: 12 December 2021

Accepted: 7 February 2022

Published: 10 February 2022

Publisher's Note: MDPI stays neutral with regard to jurisdictional claims in published maps and institutional affiliations.

Copyright: (C) 2022 by the authors. Licensee MDPI, Basel, Switzerland. This article is an open access article distributed under the terms and conditions of the Creative Commons Attribution (CC BY) license (https:// creativecommons.org/licenses/by/ $4.0 /)$.

\begin{abstract}
In clinical settings, the information provided by genetic testing can explain the triggers and processes underlying clinical presentations, such as neurodevelopmental disorders, in up to one third of affected individuals. However, translating this knowledge into better and more personalized clinical management to many appears a distant target. This article presents three paradigmatic cases to exemplify how this translational effort can, at least in some instances, be undertaken today with very positive results: (a) a young girl carrying a chr. 16p11.2 duplication can be screened using targeted exams and undertake therapeutic/preventive interventions related to her genetic diagnosis; (b) a 13-year-old boy with intellectual disability and autism spectrum disorder carries a chr. 11q14.1 deletion, partly spanning the DLG2 gene important for synaptic function, and gained over 20 I.Q. points ostensibly due to carbolithium, prescribed in the absence of affective symptoms, exclusively following the pathophysiology pointed out by the genetic results; (c) a 58-year-old woman carries a COL3A1 gene variant responsible for the vascular form of Ehler-Danlos syndrome with colon rupture. Detection of this variant in six members of her extended family allows for better clinical management of the proband and targeted genetic counselling for family members at risk of this connective tissue disorder. The unprecedented flow of genetic information available today through new technologies, if interpreted in the light of current knowledge in clinical diagnosis and care of those with connective tissue disorders and neurodevelopmental disturbances, in biology and in neuropsychopharmacology, can promote better clinical and pharmacological treatment, disease surveillance, and management provided and incorporated into the clinical setting.
\end{abstract}

Keywords: 16p13.2 duplication; COL3A1; DLG2; Ehlers-Danlos syndrome; lithium

\section{Introduction}

Many patients presenting for clinical evaluation due to complex conditions, including cardiovascular and neurodevelopmental disorders, are increasingly viewed as having a heterogeneous collection of genetic conditions, whose diagnosis is ultimately based on a predetermined set of shared features. In the case of autism spectrum disorder (ASD), for example, multiple lines of evidence support the convergence of these numerous, individually rare but collectively common genetic causes onto a relatively limited number of functional pathways, whose derangement affects neurodevelopment in ways which are beginning to be well understood at the molecular level through cellular and animal models [1]. However, the use of this genetic knowledge in the clinical management of children and adults with 
neurodevelopmental disorders is still not widely implemented. In the clinical routine, genetics is still often viewed as a super-specialized area of expertise somewhat collateral to the mainstream clinical management of patients with behavioral disorders. In an oversimplified view, genetic testing may be able to explain in up to one third of cases why a given child has received a clinical diagnosis of autism spectrum disorder (ASD), intellectual disability (ID), and so on, but the path for clinicians, patients, and families to translate these genomic results into better clinical management is often unclear. Without a strategy in place, patients will be prescribed the same behavioral intervention, speech or occupational therapy that would have been prescribed without any prior knowledge of genetic results. Similarly, genetic information will have little influence on psychopharmacological interventions, which remain non-disease specific, directly imported into child psychiatry from adult psychiatry, not always evidence-based and usually off-label [2,3]. In brief, many clinicians appear convinced that with or without positive genetic testing and consultation, the clinical management of children and adults with NDDs will essentially follow the same trajectory. Similarly, the application of advanced genetic testing (i.e., next-generation sequencing) in identifying affected or at-risk individuals for the presence of a potential life-threatening event, such as aortic aneurysm or internal organ rupture, is not part of the assessment typically performed in most clinical centers and yet, in the case with vascular Ehler-Danlos syndrome (EDS) which we shall describe, it can be instrumental in prioritizing life-saving strategies and management.

The number of studies addressing the genetic, molecular, and neurobiological underpinnings of behavioral and somatic conditions with high heritability as a whole and at the single-patient level has undergone exponential growth over the past twenty years. This, in turn, has produced a parallel growth of knowledge in the mechanisms underlying pathophysiology, spurring interest into the exploration of novel ways to translate this knowledge into better and more personalized clinical management, often labeled "precision medicine" [4]. This article presents three paradigmatic cases embodying this latter view, with the aim to show how it is already possible today, at least in some cases, to incorporate the information provided by diagnostic genetic testing into a personalized approach able to improve clinical practice in the areas of prognostic predictions and preventive follow-up, targeted medical testing and surveillance, and innovative and personalized psychopharmacology. These approaches will be a better support to families and patients. The three cases described in this article have been directly observed, diagnosed, and followed over time by the authors during medical care services. Informed consent was obtained from parents / patients for inclusion in studies at each of the respective diagnostic centers by the authors in accordance with their institutional review boards.

\section{Actionable Genomics in Psychiatry: Example of a 16p11.2 Duplication Case Report}

CNVs in 16p11.2 are among the most frequently identified pathogenic genetic changes in autism spectrum and other neurodevelopmental disorders $[5,6]$. They exemplify the variable expressivity and pleiotropy that tends to be the norm for high-risk genetic variants: deletions of this genomic interval are strongly associated with autism and intellectual disability [7], while duplications appear to increase risk more strongly towards psychotic disorders [8]. In addition to these neurobehavioral phenotypes, these genetic changes have an impact on other phenotypes outside the central nervous system that seem to be sensitive to gene dosage; for example, people with 16p11.2 deletions have a higher BMI and lower head circumference, while the opposite phenotypes are seen in those with 16p11.2 duplications [9]. Below, we report a clinical vignette that showcases how genetic information can be used in the clinic, highlighting decision points where management would differ based on genomic data.

Case Report

We evaluated a now 16-year-old adopted female in our Genomic Psychiatry Consultation Service. She had a history of autism spectrum disorder, attention deficit and 
hyperactivity disorder, learning difficulties, trichotillomania, self-injurious behaviors, depressive disorder, and was presenting because of worsening anxiety. She had a family history of schizophrenia in her biological father, and mild intellectual disability in her biological mother. Genetic testing was obtained using a commercially available chromosomal microarray to detect deletions and duplications in the clinic setting due to her history of developmental delay, microcephaly, and ASD. It revealed a duplication of chromosome 16p11.2 (chr16:29560500-30104844 × 3, hg18). Regarding other medical comorbidities, she had agenesis of the corpus callosum, a mild distal low amplitude left hand intention tremor that she could suppress voluntarily, and no seizures or cardiac or renal anomalies were reported. A recent body mass index was 26.83, which lies at the 91st percentile for her age on the CDC growth curve for girls from 2-20 years. Her psychopharmacological regimen included sertraline for low mood and anxiety, aripiprazole for mood stabilization and irritability in the setting of an ASD, n-acetylcysteine for trichotillomania, and methylphenidate HCL for low attention.

Recommendations in collaboration with her treating clinicians were made in the context of known behavioral and medical comorbidities associated with 16p11.2 duplications, many of which the patient was already displaying (microcephaly, ASD, ADHD, and learning difficulties). Regarding her medication regimen, we analyzed the risks and benefits particularly in the context of her rare genomic variant. She was already on aripiprazole, an antipsychotic medication that has an FDA indication for irritability in the setting of ASD, and which can also lead to weight gain, metabolic abnormalities, and decreased seizure threshold [3]. An EEG was obtained in the context of episodes of head tilting, repetitive picking, and decreased response to prompts, with her history of microcephaly and agenesis of the corpus callosum; it did not capture any clinical events, or evidence of seizure activity, diminishing our concern about this phenotype. Although she has a propensity for low BMI, she was already in the 91st percentile for BMI for her age, likely being protected from additional weight gain by her genomic profile, even when using one of the atypical antipsychotics with a more benign metabolic side effect profile. However, her genomic results also highlight that she is at increased risk for seizures, and aripiprazole can decrease the seizure threshold, making this an important consideration for monitoring in her case. Conversely, she also displayed ADHD, a phenotype frequently associated with 16p11.2 duplications [7]. ADHD has an excellent response to stimulant medications, which in turn can also decrease appetite and lead to weight loss; had it not been for her current higher BMI, we would have had to pay particularly close attention given her propensity to leaner BMI because of her 16p11.2 duplication, and even consider other second line strategies if this were observed, such as alpha agonists. In addition, although structural cardiac abnormalities are seen less frequently in people with 16p11.2 duplications, they can be present, and screening for these before starting medications like stimulants, which can lead to increased risk for cardiac arrhythmias in people with congenital heart anomalies. In addition, given her high risk for schizophrenia, it is particularly important to continue active surveillance for prodromal psychotic symptoms, especially as she enters young adulthood. Based on evidence of other rare genetic conditions at ultra-high risk for psychosis, we also recommended starting omega-3 fatty acids, given their favorable risk:benefit profile [10], and their additional effect on dampening potential hypertriglyceridemia stemming from atypical antipsychotic use, like the patient's case.

From a behavioral standpoint, it was helpful to take into context the language impairments that have been previously associated with 16p11.2 duplications to ensure that academic strategies were adequately identifying her areas of relative non-verbal cognitive strengths, to target the delivery of interventions by using alternative means of communicating these. Given her susceptibility to psychosis and the beneficial effect of cognitivebehavioral therapy (CBT) in preventing transition to psychosis in high-risk individuals [11], we recommended using this treatment as the modality of choice.

Lastly, from a social support standpoint, we were able to provide parents with additional phenotypic and natural history information about 16p11.2 duplications from multiple 
resources written in lay language and with contact information for support groups of other families and individuals with 16p11.2 duplications (https:/ / www.rarechromo.org/media/ information/Chromosome\%2016/16p11.2\%20Microduplications\%20QFN.pdf, accessed on 7 February 2022). Access to these resources may decrease the feelings of isolation that families with rare genetic disorders often have. We recommended following up with genetic counseling within our team in the future to discuss family planning implications, when and if this becomes relevant for her. Her longitudinal care in our clinic has evidenced an overall decrease in her anxiety and behavioral outbursts, with occasional episodes of anxiety in response to environmental stressors that we addressed with treatment followed by a return to her baseline mood. She has also maintained a stable weight, and has been meeting her academic goals successfully in the framework of her established individualized education plan.

\section{Genetically-Driven Psychopharmacotherapy: A Paradigmatic Case of Intellectual Disability and Autism Spectrum Disorder}

The psychopharmacotherapy of ASD and intellectual disability represents a challenging area for clinicians working in the field of neurodevelopmental disorders. On the one hand, pharmacological treatments currently available to treat ASD and ID are not directly effective on core symptoms, but rather on comorbid symptoms and problematic behaviors, such as sleep disorders, hyperactivity, anxiety, depression, irritability, aggression, self-injurious behavior, and epilepsy $[2,3,12]$. On the other hand, patients with neurodevelopmental disorders display much greater interindividual variability in response to psychoactive drugs and side effect sensitivity, as compared to patients with other psychiatric and behavioral disorders [3]. Genetic testing, paired with in-depth knowledge of developmental neuroscience and psychopharmacology can begin to provide novel and personalized treatment algorithms. We hereby report a case whose drug treatment was chosen based on the results of genetic testing, yielding an unprecedented success in terms of cognitive improvement.

\section{Case Report}

A.G.Z. is a boy first observed at 13 years of age, when he was diagnosed with «Mild intellectual disability, autism spectrum disorder (severity level 1) and language disorder» according to DSM-5 diagnostic criteria [13]. A mild global developmental delay was observed in early childhood, especially for motor milestones (walking at 18 months) and for expressive language development (single words at 24 months, simple sentences at 4 years). He had difficulties interacting with peers both in school and in play contexts. Hand motor stereotypies and repetitive jumping were observed when the child was excited. At 11years-old, cognitive testing using the WISC-III yielded a Total I.Q. of 55, Verbal I.Q. 59 and Performance I.Q. 62. Starting at age 12 years, parents noticed a slowly progressive cognitive worsening, especially in reference to memory, with increasing difficulty acquiring new information and lack of consolidation of recently acquired practical skills. This patient was followed up for a total of 6 years, first at the Child and Adolescent Neuropsychiatry Unit at University Campus Bio-Medico (Rome, Italy) and subsequently at the Interdepartmental Program "Autism 0-90" of the "G. Martino" University Hospital in Messina (Italy).

Genetic testing by array-CGH, using the Human Genome CGH SurePrint G3 Microarray $4 \times 180 \mathrm{~K}$ Kit (Agilent Technologies, Santa Clara, CA, USA), unveiled a rare, maternally inherited deletion located in chr. 11q14.1 (Figure 1). This small deletion, spanning $61 \mathrm{~kb}$, involves the highly conserved exon 1 of transcript variant 9 of the DLG2 gene ("discs large MAGUK scaffold protein 2") (Figure 1). DLG2 is primarily expressed in the central nervous system (CNS), especially in the neocortex, hippocampus, and basal ganglia, and at the subcellular level in the somatodendritic compartment of neuronal cells [14]. Multiple transcript variants using alternative transcription start sites generate different DLG2 protein isoforms expressed in different neuronal cell types. DLG2, also known as PSD-93 or Chapsyn-110, belongs to the membrane-associated guanylate kinase (MAGUK) family, 
including also DLG4, also known as PSD-95 [15]. DLG2, dimerizing with DLG4, anchors NMDA glutamate receptors, $\mathrm{K}^{+}$channels, and various intracellular signaling proteins to the scaffold of the post-synaptic glutamatergic element, keeping receptors clustered together within specific synaptic hotspots [14-16]. Derangement of this mechanism is detrimental to hippocampal long-term potentiation [17]. DLG2 also interacts with neuroligins [15] and megalin [18]. DLG2 mutant mice display deficits in some forms of associative learning [19], and autism-like behaviors, including decreased sociability and increased repetitive self-grooming [20]. Rare disruptive DLG2 gene variants are associated with a variety of neurodevelopmental disorders, including schizophrenia, intellectual disability ADHD, and autism spectrum disorder [21-29], as well as with bipolar disorder [30]. The SFARI gene database (https: / / gene.sfari.org, accessed on 7 February 2022) lists DLG2 and its binding partner DLG4 as «autism genes» with scores of 2 and 1 (i.e., "strong candidate" and "high confidence"), respectively.

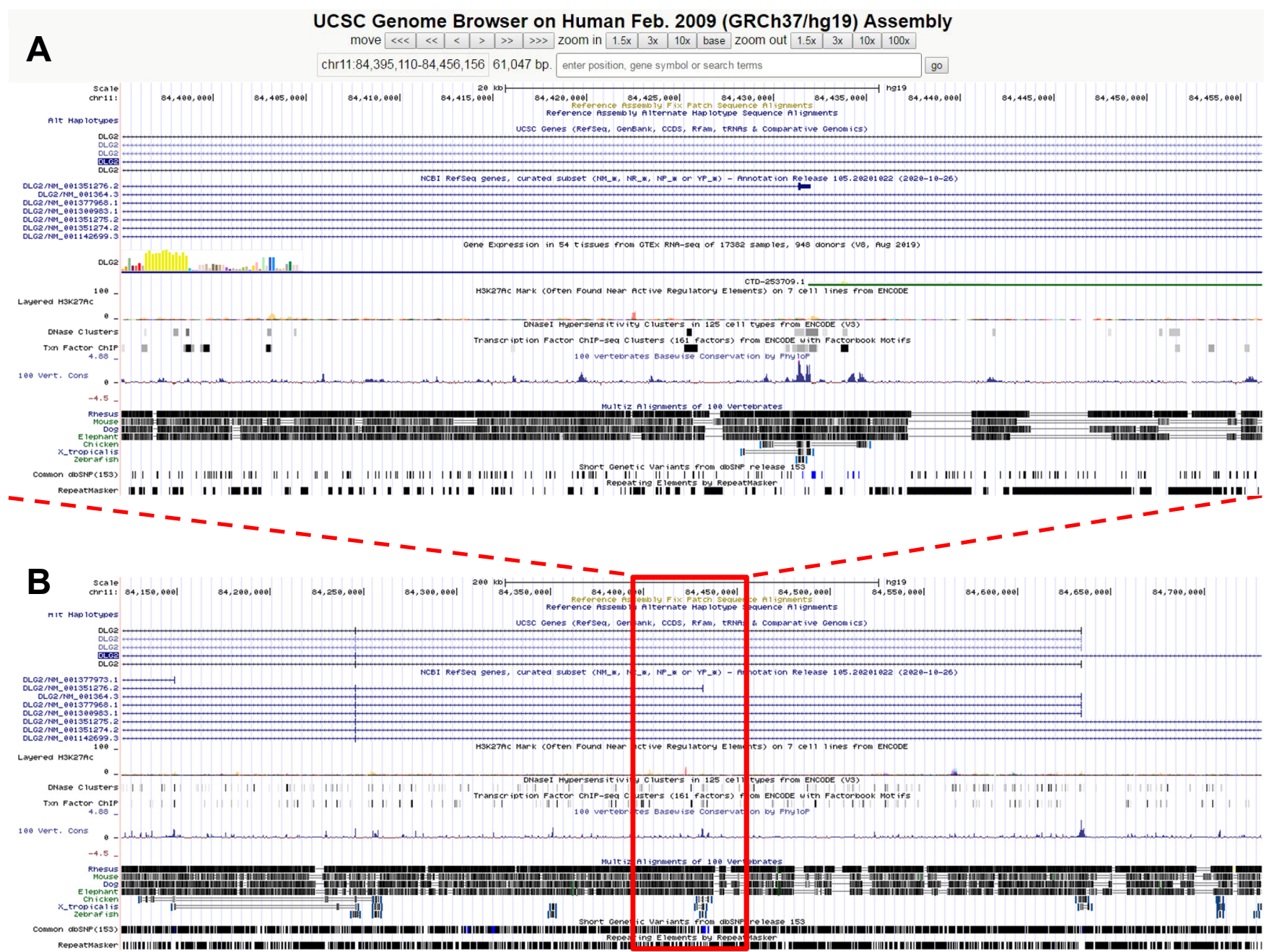

Figure 1. UCSD Genome browser views of (A) the $61 \mathrm{~kb}$ deletion located in chr. 11q14.1 carried by A.G.Z. (chr11:84,395,110-84,456,156/hg19), and (B) a 10X enlargement showing the surrounding genomic context. The deletion falls within the DLG2 gene ("discs large MAGUK scaffold protein 2"), spanning the highly conserved exon 1 of transcript variant 9.

Several points summarized above, namely (a) the strong functional link between DLG2 and NMDA glutamate receptors [14], (b) the role of DLG2 in associative learning [17,19], (c) the association of DLG2 with cognitive and neurodevelopmental disorders [21-29], and (d) the decreasing memory performance observed in our patient at early adolescence, when the brain physiologically undergoes a massive pruning of glutamatergic synapses [31], all 
led to the suggestion that therapies able to boost NMDA receptor function might have been beneficial to our patient. The first strategy we considered was to increase AMPA glutamate receptor activity, in order to remove more frequently the blockade of NMDA receptors exerted by $\mathrm{Mg}^{++}$ions, thus promoting cation influx through the NMDA channel pore [32]. Initially ampakines were considered, but CX717 was not made available for compassionate use in our patient by the producing company. Turning to psychoactive drugs more broadly available in the European market, lithium appeared as the best candidate at the time. In fact, several studies were already indicating that by elevating $\delta$-catenin, lithium could influence the clustering of AMPA receptors in the post-synaptic element of glutamatergic synapses, actively modulating neuronal activity [33]. More recently, lithium has been convincingly shown to enhance regular syncronous neuronal activity at therapeutic doses, whereas it produces epileptiform burst-like activity at overdose concentrations: both these effects are AMPA receptor-mediated and indeed lithium-induced epileptiform discharges can be effectively blocked by the AMPA receptor antagonist perampanel [34]. Collectively these studies point toward lithium as a potentially beneficial drug for this patient. Carbolithium was thus prescribed and titrated up to $450 \mathrm{mg}$ b.i.d., yielding serum levels of approximately $0.50 \mathrm{mEq} / \mathrm{L}$ which were stably maintained throughout the duration of treatment, as verified every 3-6 months. These serum levels, which represent the lower limit for affective disorders, were chosen in agreement with the family, both to minimize the probability of side-effects and because the therapeutic range for affective disorders may not have applied to this novel indication.

Lithium was started when the patient was 15 years of age. Cognitive functions were then periodically assessed using the Leiter-R [35], in order not to penalize the patient due to his expressive language impairment. His non-verbal I.Q. improved over the following months, reaching the maximum score of 94 after 8 months of low-dose lithium maintenance treatment (Table 1, Figure 2). In addition, selective visual attention steadily improved, as assessed using the Bell test [36] (Table 1). During the course of this cognitive improvement, both parents observed that the boy achieved greater adaptive functions and, sadly, greater insight into his condition. In fact, after one year of lithium therapy he suddenly asked his mother "Why am I different from all my classmates? ». Up until then, his parents claimed that he never realized the consequences of his intellectual disability, social difficulties, and limited communication skills. The achievement of this greater insight was followed by approximately one month of depressed mood, with subsequent recovery of normal mood and adaptive level. The last psychodiagnostic assessment performed under lithium treatment yielded a steady non-verbal I.Q. of 77 (July 2018 in Table 1). In September 2018, lithium was spontaneously stopped by the patient in agreement with his family, without notifying the prescribing physician. I.Q. testing performed more than one year after the interruption of lithium treatment yielded a non-verbal I.Q. of 84 (Table 1).

Table 1. Results of repeated psychodiagnostic measurements of non-verbal-I.Q. (Leiter-R) [35] and selective visual attention (Bell test) [36]. Lithium was started immediately after the February 2017 testing and was spontaneously stopped by the patient in September 2018.

\begin{tabular}{cccccccc}
\hline & & February 2017 & July 2017 & October 2017 & February 2018 & July 2018 & December 2019 \\
\hline Leiter-R & Global I.Q. & 61 & 69 & 94 & 77 & 77 & 82 \\
\hline & $\begin{array}{c}\text { Fluid } \\
\text { Intelligence }\end{array}$ & 77 & 69 & 84 & 71 & 80 & 73 \\
\hline Bell test & Brief I.Q. & 60 & 68 & 83 & 71 & 82 & 74 \\
\hline & Accuracy & -4.5 s.d. & -2.5 s.d. & -0.62 s.d. & - & - & - \\
\hline
\end{tabular}




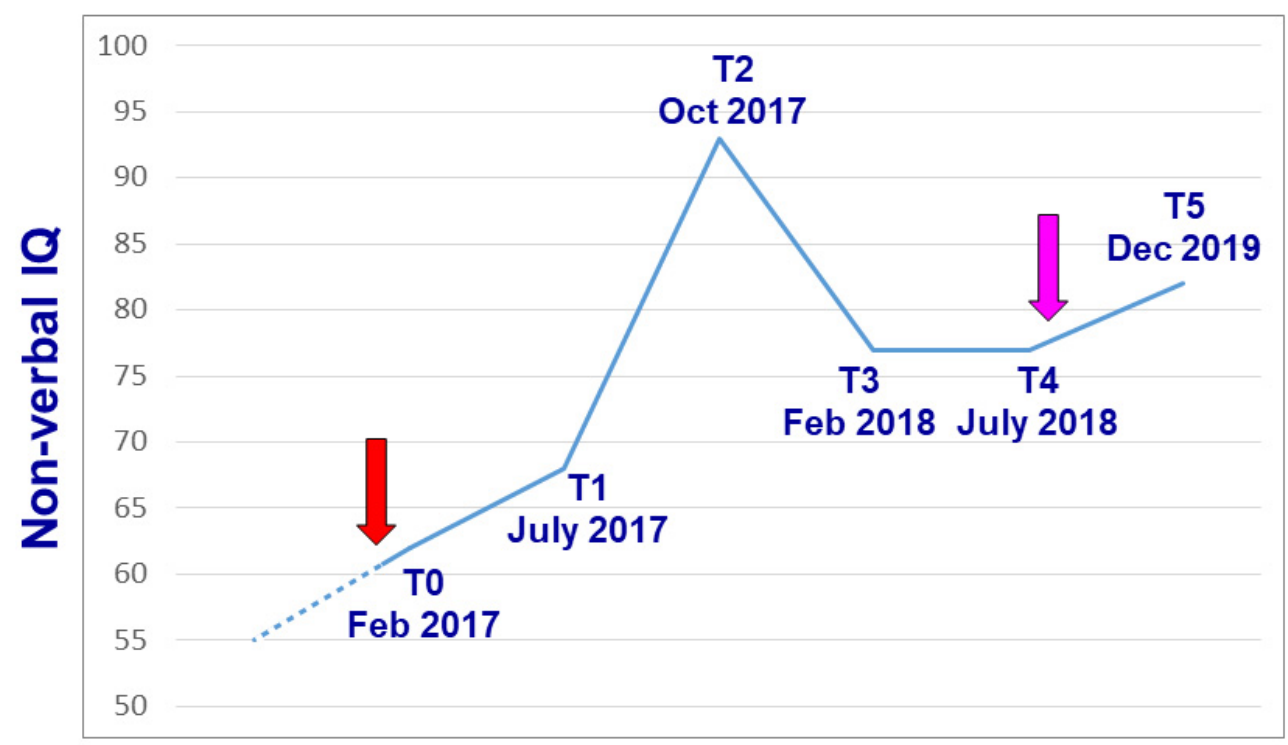

Figure 2. Variation in global non-verbal I.Q. over time, as recorded using the Leiter-R scale [35]. The beginning and the end of lithium treatment are indicated by the red and purple arrows, respectively. The hyphenated line connects T0 with a prior I.Q. measurement performed elsewhere at age 11 using the WISC-III scale (see text).

\section{COL3A1 Gene Variant and Rupture of the Colon in an Extended Family with a Connective Tissue Disorder}

Ehlers-Danlos syndrome (EDS) is included in a group of heterogeneous connective tissue disorders caused by single gene defects classified into 13 subtypes with 19 recognized dominant or recessive genes involved in their clinical presentations as listed in Table 2. Based on the 2017 international classification of Ehlers-Danlos syndrome, the 13 subtypes include classical, classical-like, cardiac-valvular, vascular, hypermobile, arthrochalasia, dermatosparaxic, kyphoscoliotic, brittle cornea syndrome, spondylodysplastic, musculocontractural, myopathic, and periodontal $[37,38]$. Most of the types of EDS have hypermobility in common, including joint dislocations/subluxations or other musculoskeletal concerns with stretchable skin, blood pressure instability, or cardiovascular problems including pain [39]. Classical EDS is characterized by joint hypermobility, easy bruising and loose skin with poor wound healing and atrophy and occurs between 1 in 5000 to 1 in 20,000 individuals [37]. The genes disturbed in classical EDS are COL5A1, COL5A2, and COL1A1. Features of this syndrome may overlap with the vascular form of EDS, including a high risk of arterial or aortic aneurysms, gastrointestinal perforation, and uterine rupture during pregnancy due to COL3A1 gene defects [40]. The relationship and delineation of EDS subtypes requires detailed genetic testing with next-generation sequencing (NGS), use of bioinformatics, and searching genomic databases. In addition to exome and genome sequencing, also disease-specific gene panels with over 75 genes for connective tissue disorders are now available for testing in the clinical setting, using services from commercially available laboratories. Genetic results in this context can impact diagnosis, prognosis, disease surveillance and monitoring, as well as genetic counseling with evaluation of at-risk family members, having a 50\% risk for autosomal dominant gene defects in first degree relatives. Individuals with vascular EDS (vEDS) are at risk of having arterial and/or aortic aneurysms in addition to internal organ rupture [37,38], as seen in several members within this family. Vascular EDS is an autosomal dominant disorder and a $50 \%$ risk for each of her first-degree relatives. Our proband and her at-risk family members including first degree relatives (siblings, children and parents) should be monitored or screened using ultrasound or CT scans and echocardiograms to determine the presence or absence of life-threatening events (e.g., aortic aneurysm) at baseline regardless of clinical symptoms, particularly if they are found to carry the same genetic defect. 
These patients should be monitored closely depending on the image results. Using regular surveillance scans to determine its size, location, and instability for surgical procedures would be needed to treat or avoid mortality if an aortic aneurysm is detected. In addition, medical treatment may be undertaken that allows restriction of blood pressure and heart function to avoid increased risk of an aneurysm if indicated to further increase viability beyond the direct colonostomy concerns raised to monitor for early signs of colon damage prior perforation, as in our probands and family members. Uterine rupture risks should also be discussed with reproductive age females as consequences of vEDS and pregnancies monitored closely. In this report we describe a proband with a variant of the COL3A1 gene causing vascular EDS with six males and females affected with spontaneous perforation of the colon over three generations in an extended family.

Table 2. Classification and genetic information about Ehlers-Danlos Syndrome (EDS) (from ref. [37] modified).

\begin{tabular}{|c|c|c|}
\hline EDS Subtype & Gene (Protein) & Inheritance \\
\hline Classical EDS (cEDS) & $\begin{array}{l}\text { Major: COL5A1 (COLLAGEN, TYPE V, } \alpha-1) \\
\text { Major: COL5A2 (COLLAGEN, TYPE V, } \alpha-2) \\
\text { Rare: COL1A1 (COLLAGEN, TYPE I, } \alpha-1)\end{array}$ & $\mathrm{AD}$ \\
\hline Classical-like EDS (clEDS) & TNXB (TENASCIN XB) & $\mathrm{AR} / \mathrm{AD} ?$ \\
\hline Vascular EDS (vEDS) & $\begin{array}{l}\text { Major: COL3A1 (COLLAGEN, TYPE III, } \alpha-1) \\
\text { Rare: COL1A1 (COLLAGEN, TYPE I, } \alpha-1)\end{array}$ & $\mathrm{AD}$ \\
\hline Kyphoscoliotic (kEDS) & $\begin{array}{c}\text { PLOD1 (PROCOLLAGEN-LYSINE, 2-OXOGLUTARATE } \\
\text { 5-DIOXYGENASE) } \\
\text { FKBP14 (FK506-BINDING PROTEIN 14) }\end{array}$ & $\mathrm{AR}$ \\
\hline Brittle cornea syndrome (BCS) & $\begin{array}{c}\text { ZNF469 (ZINC FINGER PROTEIN 469) } \\
\text { PRDM5 (PR DOMAIN-CONTAINING PROTEIN 5) }\end{array}$ & $\mathrm{AR}$ \\
\hline Periodontal EDS (pEDS) & $\begin{array}{l}\text { C1R (COMPLEMENT COMPONENT 1, } \mathrm{r} \\
\text { SUBCOMPONENT) } \\
\text { C1S (COMPLEMENT COMPONENT 1, s } \\
\text { SUBCOMPONENT) }\end{array}$ & $\mathrm{AD}$ \\
\hline Anthrochalasia EDS (aEDS) & $\begin{array}{l}\text { COL1A1 (COLLAGEN, TYPE I, } \alpha-1) \\
\text { COL1A2 (COLLAGEN, TYPE I, } \alpha-2)\end{array}$ & $\mathrm{AD}$ \\
\hline Musculocontractural EDS (mcEDS) & $\begin{array}{c}\text { CHST14 (CARBOHYDRATE SULFOTRANSFERASE 14) } \\
\text { DSE (DERMATAN SULFATE EPIMERASE) }\end{array}$ & AR \\
\hline Myopathic EDS (mEDS) & COL12A1 (COLLAGEN, TYPE XII, $\alpha-1)$ & $\mathrm{AD} / \mathrm{AR}$ \\
\hline Cardiac-valvular EDS (cvEDS) & COL1A2 (COLLAGEN, TYPE I, $\alpha-2)$ & AR \\
\hline Spondylodysplastic EDS (spEDS) & $\begin{array}{c}\text { B4GALT7 ( } \beta-1,4-G A L A C T O S Y L T R A N S F E R A S E ~ 7) \\
\text { B3GALT6 ( } \beta-1,3-G A L A C T O S Y L T R A N S F E R A S E ~ 6) \\
\text { SLC39A13 (SOLUTE CARRIER FAMILY 39-ZINC } \\
\text { TRANSPORTER, MEMBER 13) }\end{array}$ & $\mathrm{AR}$ \\
\hline Dermatosparaxis EDS (dEDS) & $\begin{array}{c}\text { ADAMTS2 (A DISINTEGRIN-LIKE AND } \\
\text { METALLOPROTEINASE WITH THROMBOSPONDIN } \\
\text { TYPE } 1 \text { MOTIF, 2) }\end{array}$ & AR \\
\hline Hypermobile EDS (hEDS) & Unknown & AD? \\
\hline
\end{tabular}

$\mathrm{AR}=$ autosomal recessive, $\mathrm{AD}=$ autosomal dominant.

Case Report

C.P. is a 58-year-old female seen in the Genetics Clinic at the University of Kansas Medical Center for discomfort in the upper quadrant of her abdomen, irritable bowel syndrome (IBS), and a history of surgical repair during the past two years due to a spontaneous transverse colon perforation without diverticulosis and a positive family history of colon perforation. She had no history of Hirschsprung's disease or megacolon prior to colon 
perforation. She had a previous history of abdominal pain and discomfort as a young child and IBS, fibromyalgia, and Raynaud's phenomenon since 18 years of age. Other review of systems was normal. The family history showed her maternal grandmother dying at 40 years of age from an unknown cause possibly involving the female reproductive tract. Her mother had a perforated colon at age 78 years and the surgical repair was attempted with some success but died two years later from poor healing and leakage from the intestine. Her 53-year-old sister had a colon resection due to imminent perforation and is under surveillance. Her 61-year-old sister had a perforation of the colon with colostomy and is under surveillance. Her maternal niece had a colon perforation age 31 years of age and is under current surveillance. Her first cousin (her mother's brother's son) was diagnosed with a perforation of the colon at six years of age and has a colostomy. Hence, there are six affected individuals including both sexes having had a perforation of the colon and/or surgical procedures performed due to an imminent risk of colon perforation.

Due to the extended family history of colon perforation in our proband and other family members, a connective tissue disorder gene panel consisting of 74 genes was ordered through a CLIA approved commercial laboratory using next-generation sequencing (NGS) with DNA isolated from saliva and buccal cells from our proband. The DNA results showed a variant of the autosomal dominant COL3A1 gene with 51 exons located on chromosome 2 at DNA coding sequence c.1961G>A; p.Gly654Glu and classified as likely pathogenic. This variant is located in the collagen triple helix repeat domain (residues 168-1196) and disrupts the Gly-X-Y motif. Numerous similar amino acid changes within this highly conserved protein motif have been reported in individuals with vascular Ehlers-Danlos syndrome [41,42]. This variant has not been reported in the Broad EXAC dataset. It has an amino acid conservation indicating that the wild-type amino acid is conserved in all 62 mammalian DNA examined with a G at position 1961; all ten computer predictive algorithms generated a deleterious change, and the Grantham distance was 98 indicating a moderate change. Hence, the laboratory-based evidence supported a likely pathogenic variant. Two of her adult daughters showed the same COL3A1 gene variant and features of a connective tissue disorder including hyperflexibility and joint pain. Other at-risk family members are scheduled to be tested and a surveillance follow-up has been planned, including non-invasive gastrointestinal imaging for colon diverticuli or other anatomical findings indicating areas of weakness, and function status.

For a COL3A1 pathogenic variant, in general major complications are seen in $15 \%$ of patients prior to genetic testing with a median survival of 50 years [43-45]. About $60 \%$ of patients are diagnosed prior to age 18 years. There are over 600 unique COL3A1 gene variants reported while the null variants, which are missing a protein product, have a milder presentation, and lower risk of bowel perforation or other major complications with increased life expectancy. The penetrance appears to be close to $100 \%$ in adults with missense or exon-skipping alterations. Gastrointestinal perforations generally involve the sigmoid colon and present in about $15 \%$ of individuals with a pathogenic variant but seldom in those with null gene variants which holds true in our family with a missense change [45]. Small bowel or stomach ruptures are less common. Bowel rupture is rarely lethal (3\%) [42] with most deaths from complications of surgery, e.g., hemorrhage or poor tissue repair or healing. Iatrogenic perforation during colonoscopy has been reported [46] and surveillance should be carefully planned and followed.

\section{Discussion}

The three cases reported in this article show how key genetic information obtained through array-based and NGS technologies, paired with a clinical consultation within the framework of a multidisciplinary approach to medical and neurodevelopmental conditions, can have a direct impact on patient management by: (a) increasing awareness about potential medical comorbidities that may be currently present and yet to be uncovered, or for which patients may be at increased risk in the future; (b) providing additional information about the natural history based on other patients with the same rare genetic changes, 
especially as it relates to diagnostic conceptualization of neuropsychiatric phenotypes; (c) providing additional resources and connecting families with support organizations specifically focused on their rare genetic change, diminishing the isolation that is often felt by families with rare genetic conditions; (d) offering additional information for family planning; (e) putting an end to a diagnostic odyssey and avoiding unnecessary invasive testing, while simultaneously focusing healthcare resources and imaging on uncovering potential comorbidities; (f) making informed or even targeted neuropsychopharmacological interventions, based on underlying neurobiological mechanisms and/or known risk profiles. Even the prescription of psychotherapy may benefit in some cases from genetic information, in reference both to indication (par. 2 here) and possibly to treatment of choice [47].

The cases carrying a 16p11.2 duplication and an inherited missense variant in the COL3A1 gene, described in par. 2 and 4, respectively, highlight the clear benefits of genetic information in the medical evaluation process and prognostic management of these patients. Detecting a duplication in chr. 16p11.2 allowed targeted medical testing to monitor propensity for seizures and to promote better pharmacological management in reference to psychostimulant prescription. Preventive administration of omega- 3 fatty acids and CBT was undertaken to counteract the vulnerability to develop psychotic ideation, associated with 16p11.2 duplication. For the COL3A1 pathogenic variant, invasive colonoscopy was avoided both for the patient and for other family members carrying the same variant, as it can lead to iatrogenic colon damage and/or perforation in these patients [46]. Importantly, colonoscopy would have likely been performed as a routine diagnostic procedure given the patient's age and symptoms, were it not for the genetic results. Non-invasive surveillance for the patient, her two daughters, and other family members was also planned accordingly. Moreover, in the case illustrated in par. 3, lithium represents an example of a personalized therapy prescribed exclusively on the basis of the pathophysiological framework derived from array-CGH analysis. In fact, patient and family history were absolutely negative for bipolar disorder, major depression, or other psychiatric disorders for which lithium is typically prescribed. All psychodiagnostic measurements performed since childhood prior to lithium treatment, yielded an I.Q. or D.Q. $<65$. During one year and a half of lithium treatment, a consistent and long-lasting improvement in cognitive functions, visual attention, adaptive functioning, and motivational drive was both recorded using psychodiagnostic testing (Table 1, Figure 2) and observed clinically. Noticeably, this improvement was still detectable more than one year after lithium was stopped (Figure 2). This outcome appears unlikely to represent a chance finding and is even more encouraging, if we consider that at the beginning of adolescence, parents were observing a decrease in memory and cognitive performance. Two separate anedoctal observations describe lithium treatment as reverting cognitive regression in patients with Phelan-McDermid syndrome due to haploinsufficiency of the SHANK3 gene $[48,49]$. Effective lithium blood levels were slightly higher in these cases than the ones proven effective in our patient $(0.7-0.8 \mathrm{vs} .0 .5 \mathrm{mEq} / \mathrm{L})$. Each observation of a single case remains anedoctal and speculative until replicated in a patient sample, because an unusually benign spontaneous evolution not related to lithium treatment, though unlikely, cannot be excluded. However, our case report and the two cases with Phelan-McDermid syndrome described above [48,49], collectively spur interest into exploring the possible therapeutic efficacy of lithium in larger samples of patients with autism and/or intellectual disability due to disruptive genetic variants affecting DLG2 [29] or other genes encoding postsynaptic glutamatergic scaffolding proteins [50].

\section{Conclusions}

We hope that case descriptions such as the ones reported in this article, which emphasize the complexities and "real world" presentation of people with psychiatric or unusual medical complications and conditions, can showcase how actionable clinical interventions based on genomic data can be put in place now, with readily available resources. Although exciting new discoveries offer the potential of directly targeting the molecular underpin- 
nings altered in rare genetic disorders, incorporating genomic data for clinical treatment in the same way that medicine factors in multiple other sources of clinical data, can lead to less missed opportunities to improve our patients' health, which is the ultimate goal of precision medicine.

Author Contributions: Conceptualization, validation, investigation, and writing —original draft preparation, M.G.B., D.M.-D.-L. and A.M.P.; writing-review and editing, A.M.P. All authors have read and agreed to the published version of the manuscript.

Funding: DMDL is supported by NIMH MH120376-02; AMP is supported by competitive intramural funding by the University of Modena and Reggio Emilia and Fondazione di Modena, and by Banca BPER.

Institutional Review Board Statement: Not applicable.

Informed Consent Statement: Not applicable.

Data Availability Statement: No data were generated.

Acknowledgments: The authors gratefully acknowledge all the patients and families who participated in this study.

Conflicts of Interest: The authors declare no conflict of interest.

\section{References}

1. Leblond, C.S.; Le, T.L.; Malesys, S.; Cliquet, F.; Tabet, A.C.; Delorme, R.; Rolland, T.; Bourgeron, T. Operative list of genes associated with autism and neurodevelopmental disorders based on database review. Mol. Cell. Neurosci. 2021, $113,103623$. [CrossRef]

2. Persico, A.M.; Arango, C.; Buitelaar, J.K.; Correll, C.U.; Glennon, J.C.; Hoekstra, P.J.; Moreno, C.; Vitiello, B.; Vorstman, J.; The European Child and Adolescent Clinical Psychopharmacology Network; et al. Unmet needs in paediatric psychopharmacology: Present scenario and future perspectives. Eur. Neuropsychopharmacol. 2015, 25, 1513-1531. [CrossRef]

3. Persico, A.M.; Ricciardello, A.; Lamberti, M.; Turriziani, L.; Cucinotta, F.; Brogna, C.; Vitiello, B.; Arango, C. The pediatric psychopharmacology of autism spectrum disorder: A systematic review-Part I: The past and the present. Prog. Neuropsychopharmacol. Biol. Psychiatry 2021, 110, 110326. [CrossRef] [PubMed]

4. Butler, M.G. Pharmacogenetics and psychiatric care: A review and commentary. J. Ment. Health Clin. Psychol. 2018, 2, 17-24. [CrossRef] [PubMed]

5. Hudac, C.M.; Bove, J.; Barber, S.; Duyzend, M.; Wallace, A.; Martin, C.L.; Ledbetter, D.H.; Hanson, E.; Goin-Kochel, R.P.; Green-Snyder, L.A.; et al. Evaluating heterogeneity in ASD symptomatology, cognitive ability, and adaptive functioning among 16p11.2 CNV carriers. Autism Res. 2020, 13, 1300-1310. [CrossRef]

6. Sanders, S.J.; He, X.; Willsey, A.J.; Ercan-Sencicek, A.G.; Samocha, K.E.; Cicek, A.E.; Murtha, M.T.; Bal, V.H.; Bishop, S.L.; Dong, S.; et al. Insights into Autism Spectrum Disorder genomic architecture and biology from 71 risk loci. Neuron 2015, 87, 1215-1233. [CrossRef]

7. Taylor, C.M.; Smith, R.; Lehman, C.; Mitchel, M.W.; Singer, K.; Weaver, W.C.; Chung, W. 16p11.2 Recurrent Deletion. In GeneReviews ${ }^{\circledR}$ [Internet]; Adam, M.P., Ardinger, H.H., Pagon, R.A., Wallace, S.E., Bean, L.J.H., Mirzaa, G., Amemiya, A., Eds.; University of Washington: Seattle, WA, USA, 1993-2021; [updated 28 October 2021].

8. Jutla, A.; Turner, J.B.; Green Snyder, L.A.; Chung, W.K.; Veenstra-VanderWeele, J. Psychotic symptoms in 16 p11.2 copy-number variant carriers. Autism Res. 2020, 13, 187-198. [CrossRef]

9. Jacquemont, S.; Reymond, A.; Zufferey, F.; Harewood, L.; Walters, R.G.; Kutalik, Z.; Martinet, D.; Shen, Y.; Valsesia, A.; Beckmann, N.D.; et al. Mirror extreme BMI phenotypes associated with gene dosage at the chromosome 16p11.2 locus. Nature 2011, 478, 97-102. [CrossRef]

10. Armando, M.; Ciampoli, M.; Padula, M.C.; Amminger, P.; De Crescenzo, F.; Maeder, J.; Schneider, M.; Schaer, M.; Managò, F.; Eliez, S.; et al. Favorable effects of omega-3 polyunsaturated fatty acids in attentional control and conversion rate to psychosis in 22q11.2 deletion syndrome. Neuropharmacology 2020, 168, 107995. [CrossRef] [PubMed]

11. Mei, C.; van der Gaag, M.; Nelson, B.; Smit, F.; Yuen, H.P.; Berger, M.; Krcmar, M.; French, P.; Amminger, G.P.; Bechdolf, A.; et al. Preventive interventions for individuals at ultra high risk for psychosis: An updated and extended meta-analysis. Clin. Psychol. Rev. 2021, 86, 102005. [CrossRef]

12. Jobski, K.; Höfer, J.; Hoffmann, F.; Bachmann, C. Use of psychotropic drugs in patients with autism spectrum disorders: A systematic review. Acta Psychiatr. Scand. 2017, 135, 8-28. [CrossRef]

13. American Psychiatric Association. Diagnostic and Statistical Manual of Mental Disorders, 5th ed.; American Psychiatric Publishing: Arlington, VA, USA, 2013. 
14. Kim, E.; Cho, K.O.; Rothschild, A.; Sheng, M. Heteromultimerization and NMDA receptor-clustering activity of Chapsyn-110, a member of the PSD-95 family of proteins. Neuron 1996, 17, 103-113. [CrossRef]

15. Irie, M.; Hata, Y.; Takeuchi, M.; Ichtchenko, K.; Toyoda, A.; Hirao, K.; Takai, Y.; Rosahl, T.W.; Südhof, T.C. Binding of neuroligins to PSD-95. Science 1997, 277, 1511-1515. [CrossRef] [PubMed]

16. Kim, E.; Niethammer, M.; Rothschild, A.; Jan, Y.N.; Sheng, M. Clustering of Shaker-type K+ channels by interaction with a family of membrane-associated guanylate kinases. Nature 1995, 378, 85-88. [CrossRef] [PubMed]

17. Carlisle, H.J.; Fink, A.E.; Grant, S.G.; O'Dell, T.J. Opposing effects of PSD-93 and PSD-95 on long-term potentiation and spike timing-dependent plasticity. J. Physiol. 2008, 586, 5885-5900. [CrossRef] [PubMed]

18. Larsson, M.; Hjälm, G.; Sakwe, A.M.; Engström, A.; Höglund, A.S.; Larsson, E.; Robinson, R.C.; Sundberg, C.; Rask, L. Selective interaction of megalin with postsynaptic density-95 (PSD-95)-like membrane-associated guanylate kinase (MAGUK) proteins. Biochem. J. 2003, 373 Pt 2, 381-391. [CrossRef]

19. Nithianantharajah, J.; Komiyama, N.H.; McKechanie, A.; Johnstone, M.; Blackwood, D.H.; St Clair, D.; Emes, R.D.; van de Lagemaat, L.N.; Saksida, L.M.; Bussey, T.J.; et al. Synaptic scaffold evolution generated components of vertebrate cognitive complexity. Nat. Neurosci. 2013, 16, 16-24. [CrossRef]

20. Yoo, T.; Kim, S.G.; Yang, S.H.; Kim, H.; Kim, E.; Kim, S.Y. A DLG2 deficiency in mice leads to reduced sociability and increased repetitive behavior accompanied by aberrant synaptic transmission in the dorsal striatum. Mol. Autism. 2020, 11, 19. [CrossRef] [PubMed]

21. Walsh, T.; McClellan, J.M.; McCarthy, S.E.; Addington, A.M.; Pierce, S.B.; Cooper, G.M.; Nord, A.S.; Kusenda, M.; Malhotra, D.; Bhandari, A.; et al. Rare structural variants disrupt multiple genes in neurodevelopmental pathways in schizophrenia. Science 2008, 320, 539-543. [CrossRef]

22. Kirov, G.; Pocklington, A.J.; Holmans, P.; Ivanov, D.; Ikeda, M.; Ruderfer, D.; Moran, J.; Chambert, K.; Toncheva, D.; Georgieva, L.; et al. De novo CNV analysis implicates specific abnormalities of postsynaptic signalling complexes in the pathogenesis of schizophrenia. Mol. Psychiatry 2012, 17, 142-153. [CrossRef]

23. De Rubeis, S.; He, X.; Goldberg, A.P.; Poultney, C.S.; Samocha, K.; Cicek, A.E.; Kou, Y.; Liu, L.; Fromer, M.; Walker, S.; et al Synaptic, transcriptional and chromatin genes disrupted in autism. Nature 2014, 515, 209-215. [CrossRef]

24. Egger, G.; Roetzer, K.M.; Noor, A.; Lionel, A.C.; Mahmood, H.; Schwarzbraun, T.; Boright, O.; Mikhailov, A.; Marshall, C.R.; Windpassinger, C.; et al. Identification of risk genes for autism spectrum disorder through copy number variation analysis in Austrian families. Neurogenetics 2014, 15, 117-127. [CrossRef] [PubMed]

25. Fromer, M.; Pocklington, A.J.; Kavanagh, D.H.; Williams, H.J.; Dwyer, S.; Gormley, P.; Georgieva, L.; Rees, E.; Palta, P.; Ruderfer, D.M.; et al. De novo mutations in schizophrenia implicate synaptic networks. Nature 2014, 506, 179-184. [CrossRef] [PubMed]

26. Alemany, S.; Ribasés, M.; Vilor-Tejedor, N.; Bustamante, M.; Sánchez-Mora, C.; Bosch, R.; Richarte, V.; Cormand, B.; Casas, M.; Ramos-Quiroga, J.A.; et al. New suggestive genetic loci and biological pathways for attention function in adult attentiondeficit/hyperactivity disorder. Am. J. Med. Genet. B Neuropsychiatr. Genet. 2015, 168, 459-470. [CrossRef]

27. Xing, J.; Kimura, H.; Wang, C.; Ishizuka, K.; Kushima, I.; Arioka, Y.; Yoshimi, A.; Nakamura, Y.; Shiino, T.; Oya-Ito, T.; et al. Resequencing and association analysis of six PSD-95-related genes as possible susceptibility genes for schizophrenia and autism spectrum disorders. Sci. Rep. 2016, 6, 27491. [CrossRef] [PubMed]

28. Reggiani, C.; Coppens, S.; Sekhara, T.; Dimov, I.; Pichon, B.; Lufin, N.; Addor, M.C.; Belligni, E.F.; Digilio, M.C.; Faletra, F.; et al. Novel promoters and coding first exons in DLG2 linked to developmental disorders and intellectual disability. Genome Med. 2017, 9, 67. [CrossRef]

29. Ruzzo, E.K.; Pérez-Cano, L.; Jung, J.Y.; Wang, L.K.; Kashef-Haghighi, D.; Hartl, C.; Singh, C.; Xu, J.; Hoekstra, J.N.; Leventhal, O.; et al. Inherited and de novo genetic risk for autism impacts shared networks. Cell 2019, 178, 850-866.e26. [CrossRef]

30. Noor, A.; Lionel, A.C.; Cohen-Woods, S.; Moghimi, N.; Rucker, J.; Fennell, A.; Thiruvahindrapuram, B.; Kaufman, L.; Degagne, B.; Wei, J.; et al. Copy number variant study of bipolar disorder in Canadian and UK populations implicates synaptic genes. Am. J. Med. Genet. B Neuropsychiatr. Genet. 2014, 165B, 303-313. [CrossRef]

31. Huttenlocher, P.R.; Dabholkar, A.S. Regional differences in synaptogenesis in human cerebral cortex. J. Comp. Neurol. 1997, 387, 167-178. [CrossRef]

32. Iacobucci, G.J.; Popescu, G.K. NMDA receptors: Linking physiological output to biophysical operation. Nat. Rev. Neurosci. 2017, 18, 236-249. [CrossRef]

33. Farooq, M.; Kim, S.; Patel, S.; Khatri, L.; Hikima, T.; Rice, M.E.; Ziff, E.B. Lithium increases synaptic GluA2 in hippocampal neurons by elevating the $\delta$-catenin protein. Neuropharmacology 2017, 113 Pt A, 426-433. [CrossRef]

34. Izsak, J.; Seth, H.; Iljin, M.; Theiss, S.; Ågren, H.; Funa, K.; Aigner, L.; Hanse, E.; Illes, S. Differential acute impact of therapeutically effective and overdose concentrations of lithium on human neuronal single cell and network function. Transl. Psychiatry 2021, 11, 281. [CrossRef] [PubMed]

35. Roid, G.; Miller, L. Leiter international performance scale-revised: Examiner's manual. In Leiter International Performance Scale-Revised; Roid, G.H., Miller, L.J., Eds.; Stoelting: Wood Dale, IL, USA, 1997.

36. Biancardi, A.; Stoppa, E. The bells test revised: A proposal for the study of attention in childhood. Psichiatr. Dell'infanzia Dell'adolescenza 1997, 64, 73-84. 
37. Malfait, F.; Francomano, C.; Byers, P.; Belmont, J.; Berglund, B.; Black, J.; Bloom, L.; Bowen, J.M.; Brady, A.F.; Burrows, N.P.; et al. The 2017 international classification of the Ehlers-Danlos syndromes. Am. J. Med. Genet. C Semin. Med. Genet. 2017, 175, 8-26. [CrossRef] [PubMed]

38. Ghali, N.; Sobey, G.; Burrows, N. Ehlers-Danlos syndromes. BMJ 2019, 366, 14966. [CrossRef] [PubMed]

39. VanderJagt, K.; Butler, M.G. Ehlers-Danlos syndrome and other heritable connective tissue disorders that impact pregnancies can be detected using next-generation DNA sequencing. Arch. Gynecol. Obstet. 2019, 300, 491-493. [CrossRef] [PubMed]

40. Colombi, M.; Dordoni, C.; Chiarelli, N.; Ritelli, M. Differential diagnosis and diagnostic flow chart of joint hypermobility syndrome/Ehlers-Danlos syndrome hypermobility type compared to other heritable connective tissue disorders. Am. J. Med. Genet. C. Semin. Med. Genet. 2015, 169C, 6-22. [CrossRef]

41. Henneton, P.; Albuisson, J.; Adham, S.; Legrand, A.; Mazzella, J.M.; Jeunemaitre, X.; Frank, M. Accuracy of clinical diagnostic criteria for patients with vascular Ehlers-Danlos Syndrome in a tertiary referral centre. Circ. Genom. Precis. Med. 2019, 12, e001996. [CrossRef]

42. Pepin, M.; Schwarze, U.; Superti-Furga, A.; Byers, P.H. Clinical and genetic features of Ehlers-Danlos syndrome type IV, the vascular type. N. Engl. J. Med. 2000, 342, 673-680. [CrossRef]

43. Pepin, M.G.; Schwarze, U.; Rice, K.M.; Liu, M.; Leistritz, D.; Byers, P.H. Survival is affected by mutation type and molecular mechanism in vascular Ehlers-Danlos syndrome (EDS type IV). Genet. Med. 2014, 16, 881-888. [CrossRef]

44. Frank, M.; Albuisson, J.; Ranque, B.; Golmard, L.; Mazzella, J.M.; Bal-Theoleyre, L.; Fauret, A.L.; Mirault, T.; Denarié, N.; Mousseaux, E.; et al. The type of variants at the COL3A1 gene associates with the phenotype and severity of vascular EhlersDanlos syndrome. Eur. J. Hum. Genet. 2015, 23, 1657-1664. [CrossRef] [PubMed]

45. Byers, P.H. Vascular Ehlers-Danlos Syndrome. In GeneReviews ${ }^{\circledR}$ [Internet]; Adam, M.P., Ardinger, H.H., Pagon, R.A., Wallace, S.E., Bean, L.J.H., Gripp, K.W., Mirzaa, G., Amemiya, A., Eds.; University of Washington: Seattle, WA, USA, 1993-2022; [updated 21 February 2019].

46. Rana, M.; Aziz, O.; Purkayastha, S.; Lloyd, J.; Wolfe, J.; Ziprin, P. Colonoscopic perforation leading to a diagnosis of Ehlers Danlos syndrome type IV: A case report and review of the literature. J. Med. Case. Rep. 2011, 5, 229. [CrossRef] [PubMed]

47. Cucinotta, F.; Ricciardello, A.; Turriziani, L.; Calabrese, G.; Briguglio, M.; Boncoddo, M.; Bellomo, F.; Tomaiuolo, P.; Martines, S.; Bruschetta, M.; et al. FARP-1 deletion is associated with lack of response to autism treatment by Early Start Denver Model in a multiplex family. Mol. Genet. Genom. Med. 2020, 8, e1373. [CrossRef] [PubMed]

48. Serret, S.; Thümmler, S.; Dor, E.; Vesperini, S.; Santos, A.; Askenazy, F. Lithium as a rescue therapy for regression and catatonia features in two SHANK3 patients with autism spectrum disorder: Case reports. BMC Psychiatry 2015, 15, 107. [CrossRef] [PubMed]

49. Egger, J.I.M.; Verhoeven, W.M.A.; Groenendijk-Reijenga, R.; Kant, S.G. Phelan-McDermid syndrome due to SHANK3 mutation in an intellectually disabled adult male: Successful treatment with lithium. BMJ Case Rep. 2017, 2017, bcr2017220778. [CrossRef]

50. Butler, M.G.; Rafi, S.; Manzardo, A.M. High-resolution chromosome ideogram representation of currently recognized genes for autism spectrum disorders. Int. J. Molecul. Sci. 2015, 16, 6464-6495. [CrossRef] [PubMed] 